\title{
Hospitalization For Iron Deficiency Anemia In Young Children: A Multicenter Analysis
}

\author{
Julia Segal ${ }^{1}$, Molly Mack ${ }^{1}$, Meghan McCormick ${ }^{1}$, and Ram Kalpatthi ${ }^{1}$ \\ ${ }^{1}$ Children's Hospital of Pittsburgh of UPMC
}

June 17, 2021

\begin{abstract}
Background Iron deficiency anemia (IDA) is detrimental to growth and neurodevelopmental outcomes in young children. IDA is primarily managed in the outpatient setting, though children with severe anemia may require admission. No prior studies of children with severe IDA admitted to US children's hospitals exist. The objective is to describe characteristics of children requiring admission for IDA. Procedure Using the Pediatric Health Information system database, we identified children age 0-5 years admitted from 2004-2018 with a primary diagnosis of IDA. Patient characteristics were compared by chi-square test or t-test of means. Univariate logistic regression was used to identify factors associated with readmission. We also performed a retrospective review of primary care records. Results A total of 4963 unique patients were identified, with 5202 unique hospitalizations. The mean age at admission at index hospitalization was 1.5 years with no gender difference. A trend towards an increasing number of admissions was noted in recent years. The majority of the patients received blood transfusions (87.3\%) and oral iron (61.4\%), whereas only $4.9 \%$ of patients received intravenous iron. Overall, $13.1 \%$ of patients required ICU admission, which was more common in female patients and children of Black or Asian race. Factors associated with decreased odds of readmission included blood product transfusion and use of oral iron during the index hospitalization. Conclusions IDA is a preventable condition, with potential for detrimental long-term outcomes. Trends in the number of admissions over time are concerning in light of the substantial use of hospital resources.
\end{abstract}

\section{Hosted file}

Segal Hospitalization For Iron Deficiency Anemia In Young Children- A Multicenter Analysis.docx available at https://authorea.com/users/420282/articles/526639-hospitalization-for-irondeficiency-anemia-in-young-children-a-multicenter-analysis

\section{Hosted file}

Segal Table 1.docx available at https://authorea.com/users/420282/articles/526639hospitalization-for-iron-deficiency-anemia-in-young-children-a-multicenter-analysis

\section{Hosted file}

Segal Table 2.docx available at https://authorea.com/users/420282/articles/526639hospitalization-for-iron-deficiency-anemia-in-young-children-a-multicenter-analysis

\section{Hosted file}

Segal Table 3.docx available at https://authorea.com/users/420282/articles/526639hospitalization-for-iron-deficiency-anemia-in-young-children-a-multicenter-analysis

\section{Hosted file}


Segal Table 4.docx available at https://authorea.com/users/420282/articles/526639hospitalization-for-iron-deficiency-anemia-in-young-children-a-multicenter-analysis

\section{Hosted file}

Segal Table 5.docx available at https://authorea.com/users/420282/articles/526639hospitalization-for-iron-deficiency-anemia-in-young-children-a-multicenter-analysis

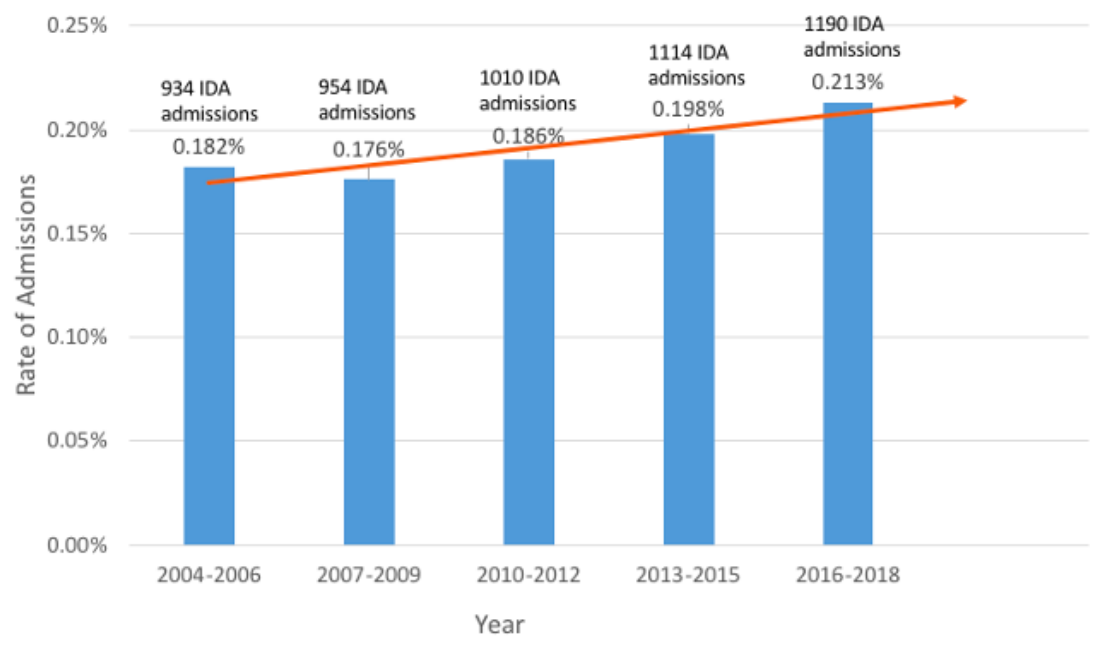

